\title{
The Effectiveness of Monetary Policy: Evidence from China
}

\author{
Qishui Chi \\ Shantou University Business School, Shantou \\ Guangdong Province, 515063, China
}

\begin{abstract}
The purpose of this paper is to provide China's empirical evidence on the real effectsof monetary policy from 1998:12 to 2012:08 by means of structural change analysis. The study shows that the structural changes of money supply at 2003:05, the end of 2008 and early of 2009 impact real output and prices efficiently, but the situations are opposite at 2000:12, 2001:06 and 2003:12. After investigating the interestrate transmission channel of monetary policy, this article draw a conclusion that the conflicting interest rate policy contrary to the overall objective of China's central bank often makes easy or tight monetary policy work inefficiently.Therefore, it matters profoundly to ensure that the interest rate policy matches the main objectives of monetary policy.
\end{abstract}

Key Words: structural change; breakpoint; monetary policy

\section{INTRODUCTION}

Money neutrality has represented the core of the Keynesian-Classicaldebate since 1936, and has received much attention from economists throughout the century. Recently, Goodwin, etc. (1994) have found evidence of substantial differences in price stickiness and the effectiveness of monetary policy across 14 US manufacturing industries. Saxegaard (2006) examines the pattern of excess liquidity in sub-Saharan Africa and itsconsequences for the effectiveness of monetary policy.The study suggests thatexcess liquidity weakens the transmission mechanism of monetary policy and thus the ability ofmonetary authorities to influence demand conditions in the economy.

The empirical literature studying the effectiveness of monetary policy has flooded by papers using cointegration technique or its derivatives such as vector autoregression (VAR), the semistructural VAR, and vector error correction (VEC), Granger causality test. For example, VARmethod is used in Goodwin, etc. (1994) and Saxegaard (2006). Meanwhile, the difference operationis also widely used in these papers before analyzing with cointegration method or its derivatives because the original time series of money stock and overall price are often unitroot processes. The conclusions of these literature using cointegration method or its derivatives are not reliable if the sequences of monetary aggregates are piecewise smooth and the output series or the overall price has a unit root. The reasons are expounded in detailas follows:

Firstly, the cointegration method and its derivatives can only be used when two or more time series are in the same order of integration. That is to say, the cointegrationmethodology doesn't work correctly if output or overall price is a unit-root series, while money supply is a piecewise continuous one.

Secondly, although the outcome of difference operation for a unitroot series is as same as that for a piecewise stationary sequence, the missing information for short-term change in these two kinds of series is different. The difference operation will change the spectrum structure of 
data generation process (DGP) for a unit root sequence, while this can't happen for a piecewise stationary series in which breakpoints will be treated wrongly as singular values.

Therefore, the structural change test should be carried out to judge whether a sequence is a real unitroot process or not if Dickey-Fuller, Augmented Dickey-Fuller or Phillips-Perron test shows the sequence isn't a stationary one. The study shows that China's monetary aggregates are piecewise smooth rather than unit root series. The structural changes of monetary aggregates have great impacts on the real output and prices. It's necessary to review literature about structural changes of macroeconomic time series because I attempt to investigate the real effects of monetary policy from a new perspective.

The breakpoint test for time series can be traced back to1960s.Chow (1960) adopts Friedman's theory of consumption and the related data of US auto consumption during the period 19211957 to verify whether there is an exogenousbreakpoint in 1954. The viewpoint that most macroeconomic sequences are characterized by astochasticrather than deterministic nonstationarity has dominated the academia of structural change until the seminal study ofPerron (1989) published. Depending on Dickey \& Fuller (1981) method, Nelson \&Plosser (1982) findsevidence in favor of the unit root hypothesis for 13 out of 14 USannual macro series. It means that current shock would have a permanent effect on the long-run macroeconomic aggregateand the series has no tendency to revert to its equilibrium status or stable path.Applying the methods advocated by Phillips \&Perron (1988) or Campbell \&Mankiw(1988), a lot of study such as Wasserfallen (1986), Perron (1988) also affirm that most macroeconomic series have a unit root. However, Perron (1989) argues that the unitroot behavior could be due to the failure to account for structural change. Taking the Great Depression in 1929 and the Oil Crisis in 1973 as the points of exogenous structural breaks, Perron's study draws the conclusion that the majority of macroeconomic series are not characterized by the presence of a unit root.

The empirical work of Chow (1960) andPerron (1989) are seriously criticized by many scholars because of the common defect taking some events as breakpoints in advance. Chow test would no longer be applicablewithout knowing the structural changes beforehand. Quandt (1960) suggestsoffsetting the deficiency of the previous literature by putting forward the Quandt-Chow statistics for the examination. Indeed, Andrews (1993) has calculated the critical values of Quandt-Chow statistics. However, the power of Quandt-Chow statisticsis too weak for practical application becausethe statisticsdo not subject to F-distribution. As to Perron's work, besides the Great Depression and the 1973 oil-price shock, there were other great events such as the 1964 tax cut, the Vietnam War, and the financial deregulation in 1980s to be potential breakpoints. Thus, Perron's unitroot test isconditional on a known breakpoint.

Zivot\& Andrews (1992) develops a methodology transformingPerron's unit root test into an unconditional stability test. Utilizing its asymptotic critical values obtained by Monte Carlo simulation, Zivot\& Andrews (1992) can't reject the unitroot hypothesis at the 5\% critical level for four Nelson and Plesser series. Meanwhile, Zivot\& Andrews (1992) reverses the unit root rejection inPerron (1989) for the postwar quarterly real GNP series.

By allowing the possibility of more potential breakpoints, Lumsdaine\&Papell (1997) extendsZivot andAndrews' endogenous break methodology to a two-break alternative. After reexamining the Nelson and Plosser data, Lumsdaine\&Papell (1997) has found the 7 series reject the unitroot null hypothesis at the 5\% level, and 9 series against the null at the 10\% 
level. In other words, Lumsdaine\&Papell (1997) has found more evidence against the null hypothesis than that of Zivot\& Andrews (1992), but less than Perron's.

The problem for automatic identification of endogenous breakpoints number in a given time series has not been completely solved so far, but there are some kinds of models being put forward to get some breaks of time series. Perron (1989) and Zivot\& Andrews (1992) establish the crash model (model A), the changing growth model (model B) and the both changing model (model C). By considering the possibility that two endogenous breakpoints occur over the relevant time period, Lumsdaine\&Papell (1997) bring forward to model AA, CA and CC to reexamine the unit root hypothesis for the Nelson and Plosser data. Thence, the empirical study such as Ben-David, Lumsdaine\&Papell (2003), Papell\&Prodan (2007) using model AA, $\mathrm{CA}$ and $\mathrm{CC}$ to test endogenous breakpoints of time series has become prevalent. Considering the AA, CA, and CC model can't fully describe the characteristics of China's import and export time series, Wang, etc. (2009) applies more alternative models (model BB, AB, and CB) for twobreak test.

Besides the literature Ben-David, Lumsdaine\&Papell (2003), Wang, etc. (2009) mentioned above, there are many other papers such as Kruse (2009) doing empirical study of breakpoints of economic time series in recent years. Applying the two-endogenous breakpoints models, Ben-David, Lumsdaine\&Papell (2003) tests breakpoints on the output growth paths for the 16 industrialized countries from 1870 to 1990. It shows the unitroot hypothesis has been rejected for around $75 \%$ of the countries. Most of the countries exhibit faster growth after their second breakpoints than during the period preceding the first breakpoints. Wang, etc. (2009) bring to light that China's export is a piecewise stationary series with many breakpoints correlated to big events during the period 1981:01-2006:12.

This article investigates the effectiveness of monetary policy in China by analyzing the relevant monetary data from 1998:12 to 2012:08. The plan of the paper is as follows. Section 2 demonstrates the mechanism of the output and price impact generated by structural changes of monetary aggregates due to different monetary policy. Using the bootstrap technique, Section 3 calculates the critical values for two-break test models with 165 samples. Section 4 does breakpoints test for the structural changes of logarithms of M1 and M2. Section 5 shows the relationship between structural change and monetary policy. Meanwhile, it illustrates the evidence regarding the transmission channelsthrough which monetary policy affect real economy. Section 6 draws conclusions.

\section{MODELS AND METHODOLOGY}

Suppose the time series of money stockis piecewise stationary, structural changes may happen during the period implementing easy or tight monetary policy. Let the observed data of money supply be ${ }^{M}=\{\operatorname{Mon}(1), \operatorname{Mon}(2), \ldots, \operatorname{Mon}(N)\}$. Suppose there are independent segments $s_{1}, s_{2}, \ldots, s_{q}$ corresponding to models $\operatorname{Mod}^{\left(s_{1}\right)}, \operatorname{Mod}^{\left(s_{2}\right)}, \operatorname{Mod}^{\left(s_{3}\right)}, \ldots, \operatorname{Mod}^{\left(s_{q}\right)} . \operatorname{Mod}^{\left(s_{m}\right)}$ Is an autoregressive model with the order $^{h_{m}}$, where ${ }^{m=1,2,3, \ldots, q}$. The data from the segment are generated according to:

$\operatorname{Mon}(n)=-a_{1}(n) \operatorname{Mon}(n-1)-a_{2}(n) \operatorname{Mon}(n-2)-\ldots-a_{p_{m}}(n) \operatorname{Mon}\left(n-h_{m}\right)+e(n)$

Where the ${ }^{e(n)}$ is a zero-mean white noise variable whose variance is $\sigma_{m}^{2}$. I denote the breakpoints where structural changes happen with $\lambda_{1}, \lambda_{2}, \ldots, \lambda_{q-1}$, where $\lambda_{1}<\lambda_{2}<, \ldots<\lambda_{q-1}$ According to Djurić, Kay \&Boudreaux-Bartels (1992), the desired parameters can be obtained from the following equation: 
$\left(\hat{q}, \hat{J}_{q-1}, \hat{H}_{q}\right)=\arg \min _{k, j_{k-1}, P_{k}}\left\{\frac{1}{N-k} \times\left[-\sum_{i=1=l=\lambda_{t-1}+1}^{k} \sum_{i-1}^{\lambda_{1}-1} \ln f\left(\operatorname{Mon}[l] \mid \operatorname{Mon}_{\lambda_{1-1}, l-1, p_{k}}\right)+\ln \frac{\prod_{l=1}^{k-1}(N-k-l)}{(k-1) !}+k \ln (H+1)\right]\right\}$

Where ${ }^{k \in(1,2, \mathrm{~L}, Q)}$, Thus segments'number ${ }^{q}$, breakpoints ${ }_{q-1}=\left[\lambda_{1}, \lambda_{2}, \ldots \lambda_{q-1}\right]$ autoregressive models' orders $H_{q}=\left[h_{1}, h_{2}, \ldots, h_{q}\right]$ could be estimated.

Suppose the time series of monetary aggregate is piecewise stationary, the jarless money supply would generally result in stable rather than dramatic changes of output and prices. By contrary, the breakpoint $\lambda_{x+1}$ between $s_{x}$ and $s_{x+1}$ means the statistical characteristics of time series $M$ has changed and the shift will make the real GDP or prices fluctuate dramatically. Consequently, it is reasonable and important to check out the breakpoints of time series $M$ to estimatethe trend of the output or the overall price levelafter the structural change occurs.

From the introduction of this article, it's clear that the theoretical foundation of the model AA, CC and CA for the two-break test advanced by Lumsdaine\&Papell (1997) is based on the onebreak test brought forward by Zivot\& Andrews (1992). The null hypothesis for three models A, B and C inZivot\& Andrews (1992) is:

$y_{t}=\mu+y_{t-1}+e_{t}$

Where $\varepsilon_{t}$ is a zero-mean stationary innovation. The alternative hypothesis stipulates that the data generating process can be represented by a trend-stationary process with a one-time break in the trend occurring at an unknown date. Three versions of alternative models considered in Zivot\& Andrews (1992) are:

$\begin{array}{ll}\text { model A: } & y_{t}=\hat{\mu}^{A}+\hat{\theta}^{A} D U_{t}(\hat{\lambda})+\hat{\beta}^{A} t+\hat{\alpha}^{A} y_{t-1}+\sum_{j=1}^{k} \hat{c}_{j}^{A} \Delta y_{t-i}+\hat{e}_{t}, \\ \text { model B: } & y_{t}=\hat{\mu}^{B}+\hat{\beta}^{B} t+\hat{\gamma}^{B} D T_{t}^{*}(\hat{\lambda})+\hat{\alpha}^{B} y_{t-1}+\sum_{j=1}^{k} \hat{c}_{j}^{B} \Delta y_{t-i}+\hat{e}_{t}, \\ \text { model C: } & y_{t}=\hat{\mu}^{C}+\hat{\theta}^{C} D U_{t}(\hat{\lambda})+\hat{\beta}^{C} t+\hat{\gamma}^{C} D T_{t}^{*}(\hat{\lambda})+\hat{\alpha}^{C} y_{t-1}+\sum_{j=1}^{k} \hat{c}_{j}^{C} \Delta y_{t-i}+\hat{e}_{t},\end{array}$

Where $D U_{t}$ and $D T_{t}$ are dummy variables. $D U_{t}(\hat{\lambda})=1$ and $D T_{t}^{*}(\hat{\lambda})=t-T \lambda$ when $t>T \lambda ; D U_{t}(\hat{\lambda})=0$; $D U_{t}(\hat{\lambda})=0$ when $t \leq T \lambda$.

The $k$ extra regressors in the equations above are added to eliminate possible nuisanceparameter dependencies in the limit distributions of the test statistics caused by temporal dependence in the disturbances. The number of $k$ is determined by a test of the significance of the estimated coefficients ${ }^{\hat{c}_{k}^{i}}$. Working backward from $k=k$, this article choose the $1^{\text {st }}$ values of $k$ such that the t-statistics on $\hat{c}_{k}^{i}$ is greater than 1.6 which also being chosen by Zivot\&Andrews (1992), Perron (1989), Ben-David, Lumsdaine\&Papell (2003) and Papell\&Prodan (2007).

After doing the Ordinary Least Square (OLS) regression for the three equations respectively for every possible endogenous breakpoint $T B \in[2, T-1]$ the estimated values of $\hat{\alpha}^{i}$ and one-side $t$ statistic ${ }^{t} \alpha^{\prime}(\lambda)$ for testing the null hypothesis $\alpha=1$ could be obtained. Let $\hat{\lambda}_{\text {in }}^{i}$ denote the minimizing values for model A, B or C, the null hypothesis would be rejected if the following expressions come into existence:

$\inf _{\lambda \in \Lambda} t_{\hat{\alpha}^{i}}(\lambda)<K_{\mathrm{inf}, \alpha}^{i} \quad i=A, B, C$ 
Where $K_{\mathrm{inf}, \alpha}^{i}$ denotes the asymptotic distribution of $\inf _{\lambda \in \Lambda} t_{\hat{\alpha}^{i}}(\lambda)$ in various significance level. Let $k=0$ and $T \rightarrow \infty$ then:

$\inf _{\lambda \in \Lambda} t_{\hat{\rho}^{\prime}}(\lambda) \stackrel{d}{\rightarrow} \inf _{\lambda \in \Lambda}\left(\int_{0}^{1} W^{i}(\lambda, r)^{2} d r\right)^{-1 / 2} \times\left(\int_{0}^{1} W^{i}(\lambda, r) d w(r)\right), \quad i=A, B, C$

Lumsdaine\&Papell (1997) does the ADF unit root test according to the following equation:

$y_{t}=\Xi^{\prime} Z_{t-1}+\varepsilon_{t}$

Where $Z_{t-1}=\left[Z_{t}^{1}, 1,\left(y_{t}-\bar{\mu}_{0} t\right), t+1, D U 1_{t+1}, D U 2_{t+1}, D T 1_{t+1}, D T 2_{t+1}\right]$ and $\Xi$ denotes a transformed parameter vector. Similar to the case of one-break model, the values of dummy variables are determined by breakpoints $T B_{n}, D U n_{t}=1$ and $D T n_{t}=t-T B_{n}$ as long as ${ }^{t>T B_{n}, i=A, B, C}$ otherwise. The equation $\lambda=T B_{n} / T$ means the locations of two breakpoints which are neitheridenticalnor conjoint. The values range $\Lambda$ of $\lambda=\left[\lambda_{1}, \lambda_{2}\right]$ is a close subset $(0,1) \times(0,1)$. The null hypothesis that the original time series is a piecewise trend stationary process should be $\alpha=0$ because DGP transformed from original time series intoone order difference form.

Then $\hat{\alpha}$ and its $t$-statistics can be acquired by carrying out the OLS regression in turn with every $\lambda=\left[\lambda_{1}, \lambda_{2}\right]$ in $\Lambda$ for model ${ }^{i} . \lambda$ Corresponding the minimum values of $t$-statistics are most possibly to be breakpoints. Then, by definition the paper get the following expression:

$\hat{\lambda}_{\text {inf }}^{i}=\left(\hat{\lambda}_{\text {linf }}^{i}, \hat{\lambda}_{\text {inf }}^{i}\right), t\left[\hat{\lambda}_{\text {inf }}^{i}\right]=\inf _{\lambda \in \Lambda} t_{\hat{\alpha}^{i}}(\lambda){ }_{i=A A, B B, C C, C A, C B, A B}$

Here more alternative models are applied by us for two-break test.

If

$t\left[\hat{\lambda}_{\text {inf }}^{i}\right]<k_{\text {inf, } \beta}^{i}$

The null hypothesis would be rejected. That is to say, the alternative one that the time series is a segment-trend-stationary sequence would be accepted.

\section{CRITICAL VALUES GENERATED FROM MONTE CARLO SIMULATION}

Although Lumsdaine\&Papell (1997) figures out the critical values of two-break test for 125 observations, this article can't use them because there are 165 observations for each time series of monetary aggregates. For the accuracy of the two-break test, I simulate the critical values for exact sample size $(T=165)$ through Monte Carlo Method.

The discrete distribution of ${ }^{i n_{\lambda \in \Lambda}} t_{\alpha^{\prime}}(\lambda)$ is needed to be generated to get the critical values mentioned above. The key steps for obtaining the distribution are as follows:

1. To get mathematical sets $\{g / i\}_{j=1}^{J}$ for unitroot series with $T$ samples through random generation:

2. To gain the values of ${ }^{t}\left[\hat{\lambda}_{\text {inf }}^{i}\right]$ after regressing for model AA, CC and CA with $\{9 \%$ o $\}$ generated by the first step

3. To obtain the discrete distribution $\left\{t_{j}\left[\lambda_{\mathrm{inf}}^{\hat{i}_{\mathrm{in}}}\right]: j=1, \mathrm{~K} J\right\}$ of $\inf _{\lambda \in \wedge} t_{\hat{\alpha}^{i}}(\lambda)$ and its corresponding significant level of one-side-test critical values. 
The calculating steps of the Monte Carlo simulation overcoming the possible correlation of the time series are as follows:

1. To acquire the coefficients $\phi \mathrm{i}(\mathrm{i}=1,2, \ldots, \mathrm{p}), \theta \mathrm{j}(\mathrm{j}=1,2, \ldots, \mathrm{q})$ and standard deviation of residual by fitting one-order difference of time series being tested with the $\operatorname{ARMA}(\mathrm{p}, \mathrm{q})$ model, that is, let $A(L) \Delta y_{t}=B(L) \varepsilon_{t}$ where $\varepsilon_{t} \sim$ i.i.d. $N\left(0, \sigma^{2}\right)$ and $L$ is a lag operator;

2. To generate the unit-root series $\{y \%$ by substituting normal pseudo random numbers with a stand deviation $\sigma=e$ and a zeromean into the ARMA model estimated;

3. To get mathematical sets $\left\{g_{t}\right\}_{j=1}^{J}$ by repeating the calculating procedures for $J$ times.

Lumsdaine\&Papell (1997) gets the critical values for 125 observations by taking the equation $\Delta \mathrm{YT}=\varepsilon_{\mathrm{t}}$ as DGP. In addition, Lumsdaine and Papell's study draws a conclusion that there isn't significant difference among the three ways generating the critical values for two-break test after the other two methods were discussed.

Tons of calculation is needed to fit every single time series if the ARMA model is applied to get critical values. Therefore, I use the equation $\Delta \mathrm{YT}=\varepsilon \mathrm{t}$ as DGP for generating random series and thus getting critical values. The main steps are as follows:

1. Letting the initial value $\mathrm{y} 1=0$ and taking $\Delta_{\mathrm{yt}}={ }_{\mathrm{t}}$ as DGP, a time series $\{Y T\}$ with 165 data is generated by random;

2. I obtain ${ }^{t\left[\lambda_{\mathrm{inf}}^{\hat{i}_{\mathrm{f}}}\right]}$ by substituting $\{\mathrm{yt}\}$ into Model AA, BB, CC, CA, CB and AB and then by doing recursive regressions for all of possible breakpoints at $\lambda_{1}, \lambda_{2} \in[0.1,0.9]$;

3. Ultimately, I get the critical values which are shown in table 1 by repeating the steps for 4,999 times.

Table 1 Critical values for two-break models

\begin{tabular}{cccccccccccc}
\hline model & $1 \%$ & $2.50 \%$ & $5 \%$ & $10 \%$ & $15 \%$ & $50 \%$ & $85 \%$ & $90 \%$ & $95 \%$ & $97.5 \%$ & $99 \%$ \\
\hline AA & -6.5826 & -6.3067 & -6.0719 & -5.7796 & -5.6212 & -4.9089 & -4.1511 & -3.6374 & -3.6374 & -3.3026 & -2.8651 \\
BB & -6.5830 & -6.2722 & -6.0275 & -5.7188 & -5.5158 & -4.7477 & -4.0460 & -3.9070 & -3.6678 & -3.4290 & -3.2324 \\
CC & -7.1868 & -6.9026 & -6.6971 & -6.4500 & -6.2756 & -5.5687 & -4.8895 & -4.7338 & -4.5082 & -4.2935 & -4.0731 \\
CA & -6.9522 & -6.6511 & -6.4006 & -6.1174 & -5.9571 & -5.2505 & -4.5431 & -4.3526 & -4.0889 & -3.8521 & -3.5583 \\
CB & -6.9028 & -6.5689 & -6.3169 & -6.0552 & -5.8807 & -5.1566 & -4.4998 & -4.3562 & -4.1296 & -3.9147 & -3.7149 \\
AB & -6.6286 & -6.3374 & -6.0718 & -5.7896 & -5.6154 & -4.8974 & -4.1668 & -3.9596 & -3.5904 & -3.2558 & -2.8406 \\
\hline
\end{tabular}

Note: 5,000 repetitions under the null hypothesis $\Delta_{\mathrm{YT}}=\varepsilon_{\mathrm{t}}$ with 165 observations. 

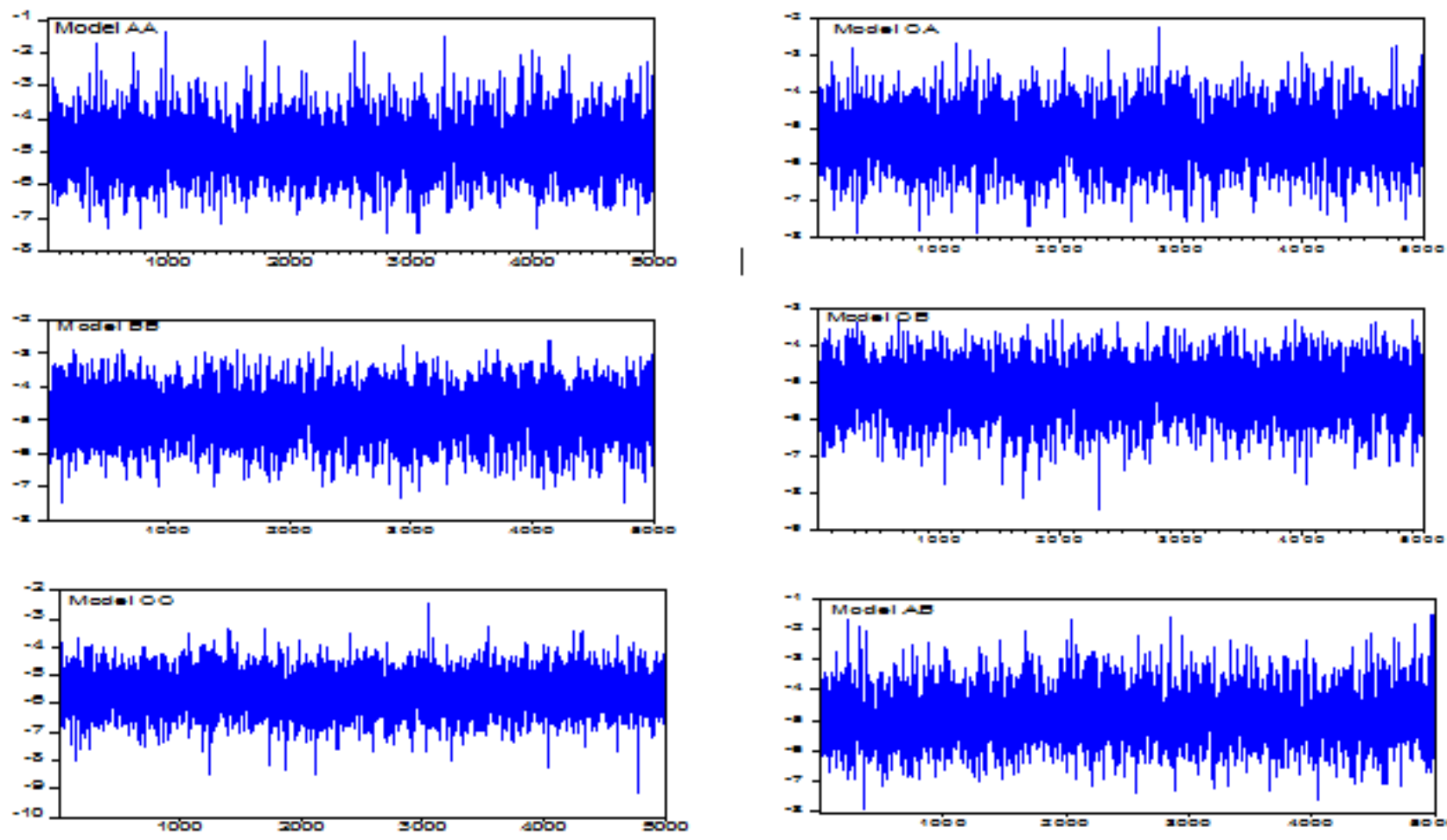

Fig 1. ${ }^{t\left[\hat{\lambda}_{i n f}^{i}\right]}$ Based on 5,000 replications

As the appendix indicates, I get the histograms and density plots of $\inf _{\lambda \in \Lambda} t_{\hat{\alpha}^{\prime}}(\lambda)$ for six models simultaneously.

\section{Data}

\section{EMPIRICAL RESULTS OF BREAKS TESTS}

I choose variables ofnarrow money (M1), broad money (M2), real GDP growth rate, CPI, PPI, CGPI (Corporate Goods Price Indices), Required Reserve Ratio (RRR), Central Bank's interest rates, etc. to investigate the effectiveness of China's monetary policy. As the appendix shows, all of data are obtained from IFS CD-ROM offered by IMF, China's Central Bank (PBOC) or National Bureau of Statistics of China (NBS). Linear-match last method, which is one of high frequency conversion techniques, is used to get Monthly GDP growth rates from their quarterly data.

I am investigating the relationship among the structural breaks of monetary aggregates, the output growth rate and the overall price level. As to monetary aggregates, a considerable amount of empirical work in literature such as Berument\&Doğan (2003) use the time series of narrow money and broad money to study the effectiveness of monetary policy. I use M1 and M2 to resume this debate, but the method being applied in this article is totally different from the literature mentioned above.

Time series M1 and M2 observed at Monthly frequencies exhibit cyclical tracks that recur every Month. In order to remove these cyclical seasonal movements, and then extract the underlying trend component of time series, it's essential to make seasonal adjustments for the original data.Apparently, the time series of China's monetary aggregates have the characteristics of seasonal variation. Therefore, it is of great necessities to adjust the original series.

The additive modus for seasonal adjustment should be used if the seasonal component in economic series is constant. On the other hand, the multiplicativeone should be employed 
when the seasonal component shows the characteristic of changing proportionally with the trend. The later one should be chosen in this article because the seasonal factors in China's monetary aggregates vary with the trend.Recently, X-12-ARIMA which includes essentiallyall the capabilities of X-11-ARIMAand X-11 is developed. For the advantages of the X-12-ARIMA providing many enhancements in model selection and diagnostics, this method is employed to remove the seasonal factor of M1 and M2 in this article.

Finally, I take the natural logarithms for the time series of China's monetary aggregates adjusted by X-12-ARIMA method to eliminate the influence of heteroscedasticity.

\section{Unit root test}

It is required to test the stationarity of time series before performing the unit root test with structural breaks. The unit root test with structural breaks would make no sense if the original series is stationary.

The ADF test for $\alpha=0$ is processed for the three seasonal adjusted serieslog M1 and log M2 in the following equation:

$\Delta y_{t}=\mu+\beta t+\alpha y_{t-1}+\sum_{i=1}^{k} c_{i} \Delta y_{t-i}+\varepsilon_{t}, \quad \varepsilon_{t} \sim \operatorname{iid} N\left(0, \sigma^{2}\right)$

The lag length is determined by Schwarz Information Criterion (SIC). The results are presented in the following table:

Table 2 ADF unit root test results

\begin{tabular}{ccccccc}
\hline Series & \multirow{2}{*}{ Test form } & \multirow{2}{*}{$t_{\alpha}$} & 1\% level & $\begin{array}{c}\text { Critical value } \\
5 \% \text { level }\end{array}$ & $10 \%$ level & Lag length (SIC \\
\hline $\log$ M1 & $(\mathrm{c}, \mathrm{t}, 0)$ & -2.5434 & -4.0164 & -3.4382 & -3.1433 & 4 \\
$\log \mathrm{M} 2$ & $(\mathrm{c}, \mathrm{t}, 0)$ & -2.0826 & -4.0150 & -3.4375 & -3.1429 & 0 \\
$\mathrm{D}(\log \mathrm{M} 1)$ & $(\mathrm{c}, 0,1)$ & $\mathbf{- 4 . 2 9 0 3}$ & -3.4715 & -2.8795 & -2.5764 & 3 \\
$\mathrm{D}(\log \mathrm{M} 2)$ & $(\mathrm{c}, 0,1)$ & $\mathbf{- 1 3 . 4 7 6 4}^{\mathrm{a}}$ & -3.4707 & -2.8792 & -2.5762 & 0 \\
\hline
\end{tabular}

Note: the letter a in this table denotes the rejection of null hypothesis at the $1 \%$ critical level.

Table 2 shows thatlog M1 and log M2 are integrated of order one. Therefore, it is essential to do structural breakpoints tests.

\section{One-break test}

Three versions of Zivot andAndrews' one-break test, model A, B, and C, are employed to investigate the unit-root hypothesis for the three time series of China's monetary aggregates. Table 3 shows the percentage points of the asymptotic distribution of $\inf _{\lambda \in \wedge} t_{\hat{\alpha}^{\prime}}(\lambda)$ for the three models by the study of Zivot\& Andrews (1992).

Table 3 Percentage points of the asymptotic distribution of $\inf _{\lambda \in \lambda} t_{\hat{\alpha}^{\prime}}(\lambda)$

\begin{tabular}{cccc}
\hline Percentage & $1 \%$ & $5 \%$ & $10 \%$ \\
\hline Model A & -5.34 & -4.80 & -4.58 \\
Model B & -4.93 & -4.42 & -4.11 \\
Model C & -5.57 & -5.08 & -4.82 \\
\hline
\end{tabular}

Then, according to the procedure outlined in previous section and table 3 , the results of onebreak test can be gotten. 
Table 4The results of one-breakpoint test

\begin{tabular}{cccccccccc}
\hline Series & Model & $T B$ & $\hat{\alpha}$ & $t_{\hat{\alpha}}$ & $\hat{\theta}$ & $t_{\hat{\theta}}$ & $\hat{\gamma}$ & $t_{\hat{\gamma}}$ & $k$ \\
\hline \multirow{2}{*}{ M1 } & A & $2009: 02$ & -0.2149 & $\mathbf{- 6 . 0 4 6 0}$ a & 0.0209 & 4.9772 & & & 11 \\
& B & $2006: 02$ & -0.1007 & -3.3808 & & & 0.0002 & 1.6976 & 7 \\
& C & $2009: 02$ & -0.0935 & -3.7497 & 0.0267 & 5.6289 & -0.0007 & -4.2125 & 4 \\
\multirow{2}{*}{ M2 } & A & $2008: 12$ & -0.1817 & $-6.7464^{\mathrm{a}}$ & 0.0193 & 6.2913 & & & 3 \\
& B & $2006: 08$ & -0.0894 & -3.0703 & & & 0.0002 & 1.9132 & 3 \\
& C & $2009: 01$ & -0.1618 & -4.9886 & 0.0209 & 6.0316 & -0.0001 & -1.5451 & 1 \\
\hline
\end{tabular}

Note: the letter a in this table denotes the rejection of null hypothesis at the $1 \%$ critical level.

The test results for model A which only has the intercept drift being considered indicate that the null hypothesis can be rejected at the1\% critical level. For M1, there is a structural breakpoint occurring at 2009:02. For M2, the date for happening structural change is2008:12. The coefficients for the dummy variables of intercept item are 0.0209 and 0.0193 . Therefore, it's evident from the two positive numbers that PBOC tried to stimulate economic recovery during the financial crisis.

\section{Two-break test}

In the case of China's money supply, many affecting events have happened during 1998:122012:08. Theoretically, more than one event resulting in structural change of money stock may exist. Therefore, model AA, CA, CCadvanced byLumsdaine and Papell (1997) and model BB, AB, CBbrought forward by Wang, etc. (2009) are also employed to investigate structural changesof China's money supply. Furthermore, I use the critical values which are given in table 1 for twobreak models with 165 observations. The results for the three versions of two-breakpoint test are present as follows:

Table 5 the results of two-breakpoint test

\begin{tabular}{|c|c|c|c|c|c|c|c|c|}
\hline Series & Model & $\hat{\alpha}$ & $T B_{n}$ & $\hat{\theta}_{1}, \hat{\theta}_{2}$ & $t_{\hat{\theta}_{\hat{1}}}, t_{\hat{\theta}_{2}}$ & $\hat{\gamma}_{1}, \hat{\gamma}_{2}$ & $t_{\hat{\gamma}_{1}}, t_{\hat{\gamma}_{2}}$ & $k$ \\
\hline \multirow{12}{*}{ M1 } & \multirow[t]{2}{*}{$\mathrm{AA}$} & -0.2237 & $2003: 05$ & 0.0078 & 2.2181 & & & 11 \\
\hline & & $\left(-6.3421^{b}\right)$ & 2009:02 & 0.0264 & 5.4652 & & & \\
\hline & \multirow[t]{2}{*}{ BB } & -0.1821 & $2008: 10$ & & & 0.0014 & 4.4328 & 4 \\
\hline & & $(-5.0361)$ & 2010:08 & & & -0.0027 & -4.7506 & \\
\hline & \multirow[t]{2}{*}{$\mathrm{CC}$} & -0.1907 & 2008:06 & -0.0083 & -1.5891 & 0.0015 & 3.7414 & 4 \\
\hline & & $(-4.8723)$ & 2010:08 & 0.0009 & 0.1382 & -0.0030 & -4.3598 & \\
\hline & \multirow[t]{2}{*}{$\mathrm{CA}$} & -0.2231 & 2003:05 & 0.0057 & 1.4659 & -0.0002 & -1.2924 & 11 \\
\hline & & $(-6.3406)$ & 2009:02 & 0.0280 & 5.6279 & & & \\
\hline & \multirow[t]{2}{*}{ CB } & -0.1618 & 2008:06 & -0.0138 & -2.4498 & 0.0022 & 4.5310 & 4 \\
\hline & & $(-5.1098)$ & 2010:02 & & & -0.0033 & -4.8696 & \\
\hline & \multirow[t]{2}{*}{$\mathrm{AB}$} & -0.2191 & 2009:02 & 0.0267 & 5.4907 & & & 11 \\
\hline & & $(-6.2497 \mathrm{c})$ & 2003:12 & & & -0.0003 & -2.2716 & \\
\hline \multirow{12}{*}{ M2 } & \multirow[t]{2}{*}{$\mathrm{AA}$} & -0.1896 & 2008:12 & 0.0226 & 6.6159 & & & 3 \\
\hline & & $(-7.0480 \mathrm{a})$ & 2003:05 & 0.0046 & 2.0984 & & & \\
\hline & \multirow[t]{2}{*}{ BB } & -0.1972 & 2008:09 & & & 0.0023 & 5.3381 & 3 \\
\hline & & $(-5.3857)$ & 2009:07 & & & -0.0024 & -5.2911 & \\
\hline & \multirow[t]{2}{*}{$\mathrm{CC}$} & -0.2577 & 2001:06 & 0.0123 & 4.4388 & 0.0009 & 4.7068 & 1 \\
\hline & & $\left(-6.7054^{c}\right)$ & 2009:01 & 0.0277 & 7.8768 & $-4.1 \mathrm{E}-05$ & -0.4644 & \\
\hline & \multirow[t]{2}{*}{$\mathrm{CA}$} & -0.2652 & 2001:06 & 0.0125 & 4.6520 & 0.0009 & 4.9248 & 1 \\
\hline & & $\left(-7.6291^{a}\right)$ & 2009:01 & 0.0277 & 7.8848 & & & \\
\hline & \multirow[t]{2}{*}{$\mathrm{CB}$} & -0.2331 & 2009:01 & 0.0243 & 6.8186 & -0.0001 & -1.1589 & 1 \\
\hline & & $(-5.8852)$ & $2000: 12$ & & & 0.0006 & 2.9932 & \\
\hline & \multirow[t]{2}{*}{$\mathrm{AB}$} & -0.2443 & 2009:01 & 0.0231 & 6.5176 & & & 3 \\
\hline & & $\left(-6.8534^{a}\right)$ & $2000: 12$ & & & 0.0005 & 2.3008 & \\
\hline
\end{tabular}

Note: the values in the brackets are t-statistics of $\hat{\alpha}$ the letters $\mathbf{a}, \mathbf{b}, \mathbf{c}$ in this table denote the rejection of null hypothesis at the $1 \%, 2.5 \%$, and $5 \%$ critical levels respectively. 
The numbers in the first line for each model in table 5represent the happening dates of breakpoints and the corresponding values of $\hat{\theta}_{1}, t_{\hat{\theta}_{1}}, \hat{\gamma}_{1}, t_{\hat{\gamma}_{1}}$. The data in the second line for every single model denote the days markings for breakpoints and their corresponding values of $\hat{\theta}_{2}, t_{\hat{\theta}_{2}}$ $\hat{\gamma}_{2}, t_{\hat{\gamma}_{2}}$.

For China's narrow money, model AA rejects the unitroot null at the $2.5 \%$ level with its first break in the intercept at2003:05 and its second break at2009:02.At the 5\% critical level, the breaks have been checked out at 2009:02 and 2003:12 with model AB.

As tobroad money, the results from model $\mathrm{AA}, \mathrm{CA}$ and $\mathrm{AB}$ reject the unitroot null at the $1 \%$ critical level. For model AA, there are two breakpoints occurring at 2008:12 and 2003:05. For model CA, the dates for two breaks are 2001:06 and 2009:01respectively. For model AB, the dates for structural changes are 2009:01 and 2000:12.Meanwhile, the results from model CC reject the null at the 5\% critical level with two breaks occurring at 2001:06 and 2009:01.

\section{China's Monetary Policy}

\section{STRUCTURAL BREAKS AND MONETARY POLICY}

The ultimate objectives of monetary policy can be summarized as follows: price stability, economic growth, full employment, balance of payments.The first objective is generally taken as the primary goal of monetary policy by monetary authority. Meanwhile, the development of economy is another key goal that should be taken into account. Therefore, I mainly focus on economic growth and price stability. Figure 2 shows CPI \% change and real GDP growth rate in China from 1998:12 to 2012:08.

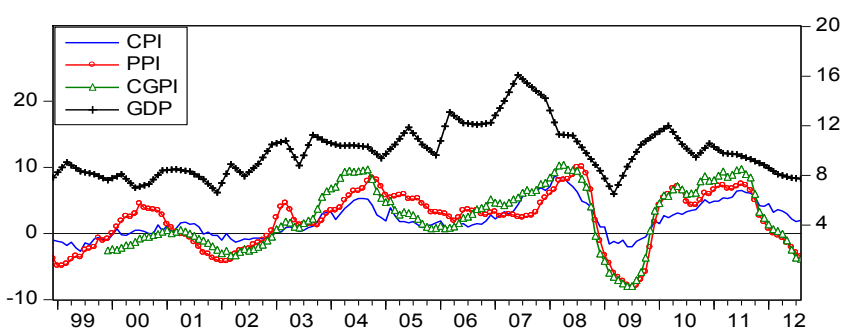

Fig. 2 Economic status and monetary policy Note: CPI, PPI, CGPI (left scale, \%), GDP (right scale, \%)

Theoretically, an appropriate monetary policy always matches the economic status. Therefore, the expansionary policy should be implemented to stimulate China's economy before August 2003 because of deflation, low growth rate of GDP within that period. Similarity, the optimal policy for the late 2008 and the year of 2009 is expansionary one because of the recession and depression due to the global financial crisis. On the other hand, the constrictive monetary policy should be applied to tighten the economy from September 2003 to August 2008 for the economic bubbles within this period.

Although China's monetary authority declared that the prudent monetary policy had been implemented during 1998:12-2007:06, PBOC had actually applied two kinds of monetary policies according to the changes of the Required Reserve Ratio (RRR), central bank's benchmark interest rates (lending rates to financial institutes, 1 year), the interest rate of required deposit reserve, the interest rate of excess deposit reserve (ERR), rediscount rate, etc. Depending on the big financial events happened during 1998:12-2012:08, it's apparent that China's monetary authority actually implemented easy monetary policy during 1998:12- 
2003:08 and 2008:09-2010:11, tight monetary policy during 2003:09-2008:08 and prudent monetary policy during 2010:12-2012:08.

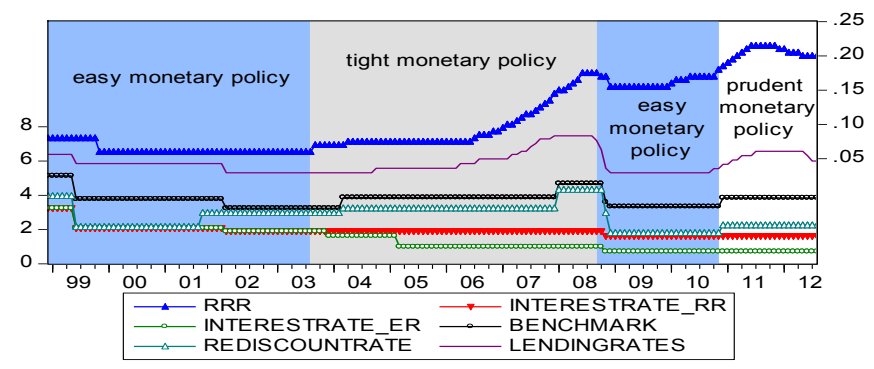

Fig. 3Requiredreserve ratio, interest rates and monetary policy Note: RRR (right scale), others variables (left scale, \%)

\section{The Structural Change and Easy Monetary Policy}

As mentioned above, PBOC implemented easy monetary policy during the periods of 1998:122003:08 and 2008:09-2010:11. According to the results of structural changes of China's monetary aggregates, I find that there are three breaks occurring within the former period. For the later period, I find breaks at the end of 2008 and the early of 2009. After 2000:12 at which a structural change of M2 occurred, the growth path should be a little bit steeper due to the value of $\hat{\gamma}$ equals to 0.0005. After 2001:06 at which another structural break of M2 happened, there should be a sudden drift upward in the level followed by a faster growth rate because of the positive values of $\hat{\gamma}$ and $\hat{\theta}$. For the breaks occurring at 2003:05, 2008:12, 2009:01 and 2009:02, time series would drift upward in the level due to the positive values of $\hat{\theta}$.

Table 6 the breaks within periods implementing easy monetary policy

\begin{tabular}{|c|c|c|c|c|c|c|}
\hline Date & $\begin{array}{l}\text { Monetary } \\
\text { aggregate }\end{array}$ & Model & $\hat{\theta}$ & $\hat{\gamma}$ & $\begin{array}{l}\text { Sudden change } \\
\text { (theoretically) }\end{array}$ & The reason for changing \\
\hline $2000: 12$ & M2 & $\mathrm{AB}$ & & 0.0005 & upward slightly & $\hat{\gamma}$ is positive, but near zero. \\
\hline \multirow{2}{*}{ 2001:06 } & M2 & $\mathrm{CC}$ & 0.0123 & 0.0009 & upward & Both $\hat{\gamma}$ and theta are positive. \\
\hline & M2 & $\mathrm{CA}$ & 0.0125 & 0.0009 & upward & Both $\hat{\gamma}$ and theta are positive. \\
\hline \multirow{2}{*}{ 2003:05 } & M1 & AA & 0.0078 & & upward & $\hat{\theta}$ is positive. \\
\hline & M2 & AA & 0.0046 & & upward & $\hat{\theta}$ is positive. \\
\hline \multirow{2}{*}{ 2008:12 } & M2 & A & 0.0193 & & upward & $\hat{\theta}$ is positive. \\
\hline & M2 & AA & 0.0226 & & upward & $\hat{\theta}$ is positive. \\
\hline \multirow{3}{*}{ 2009:01 } & M2 & $\mathrm{CC}$ & 0.0277 & $-4.1 \mathrm{E}-05$ & unsure & $\hat{\theta}$ is positive, but $\hat{\gamma}$ is negative. \\
\hline & M2 & $\mathrm{CA}$ & 0.0277 & & upward & $\hat{\theta}$ is positive. \\
\hline & M2 & $\mathrm{AB}$ & 0.0231 & & upward & $\hat{\theta}_{\text {is positive. }}$ \\
\hline \multirow{3}{*}{ 2009:02 } & M1 & A & 0.0209 & & upward & $\hat{\theta}$ is positive. \\
\hline & M1 & AA & 0.0264 & & upward & $\hat{\theta}$ is positive. \\
\hline & M1 & $\mathrm{AB}$ & 0.0267 & & upward & $\hat{\theta}$ is positive. \\
\hline
\end{tabular}

As table 6 illustrates, money supply was increased dramatically at the early of 2009 , etc. Then, had the expansionary policies worked efficiently to stimulate China's economy during the recession or depression? 


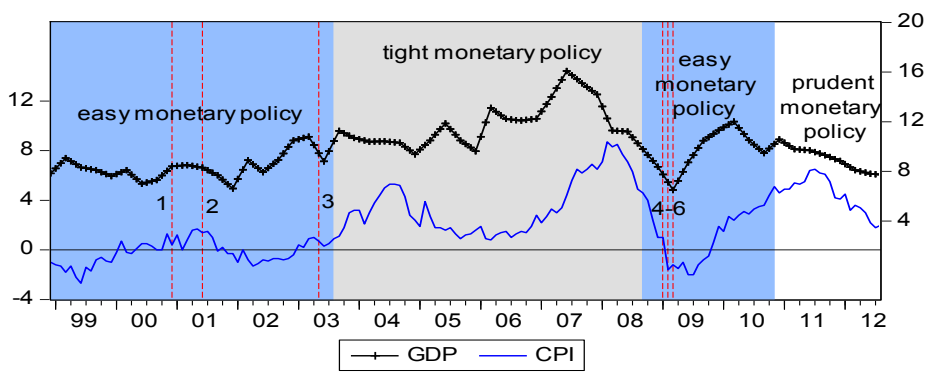

Fig. 4 breaks of money supply, real GDP and CPI change within period implementing easy monetary policy Note: GDP (right scale, \%), CPI (left scale, \%)

Figure 4 indicates that the sudden changes of narrow money or broad money at 2003:05, the end of 2008 and early of 2009 make China's economy recover efficiently. Although almost doing nothing to the severe deflation, the structural break of broad money at 2001:06 pushed the output growth upward after a short time lag. Nevertheless, the break of broad money at 2000:12didn't work well to stimulate the economy due to the small value of $\hat{\gamma}$.

Table 7The real effects of easy monetary policies on GDP and CPI

\begin{tabular}{cccccccc}
\hline \multirow{2}{*}{ break } & Date & \multicolumn{4}{c}{ Post-break trend } & \multicolumn{2}{c}{ effectiveness of the impact } \\
\cline { 3 - 6 } & & Money supply & GDP & CPI & on GDP & on CPI & Reasons for the inefficacy \\
\hline 1 & $2000: 12$ & upward & downward & upward(slightly) & ineffective & effective & \\
2 & $2001: 06$ & upward & downward & downward & ineffective & ineffective & The rediscount rate went up at 2001:09. \\
3 & $2003: 05$ & upward & upward & upward & effective & effective & \\
4 & $2008: 12$ & upward & upward & upward & effective & effective \\
5 & $2009: 01$ & upward & upward & upward & effective & effective \\
6 & $2009: 02$ & upward & upward & upward & effective & effective \\
\hline
\end{tabular}

\section{The Structural Change and Tight Monetary Policy}

From 2003:09 to 2008:08, the tight monetary policy was implemented by China's central bank. Only one break of money supply is found within this period. The value of $\hat{\gamma}$ for the breakpoint at 2003:12 is negative, and this isanother evidence of China's monetary policy tending to siege economy at that time.

Table 8 the break within period implementing tight monetary policy

\begin{tabular}{ccccccc}
\hline Date & $\begin{array}{c}\text { Monetary } \\
\text { aggregate }\end{array}$ & Model & $\hat{\theta}$ & $\hat{\gamma}$ & $\begin{array}{c}\text { Sudden change in the level, } \\
\text { slope or both (theoretically) }\end{array}$ & The reason for changing \\
\hline 2003:12 & M1 & AB & -0.0003 & downward slightly & $\hat{\gamma}$ is negative, but near zero.
\end{tabular}

However, it's hard for the monetary authority to fully achieve the goals smoothing out fluctuations in output and keeping the overall price as stable as possibledue to the near-zero negative value of $\hat{\gamma}$. 


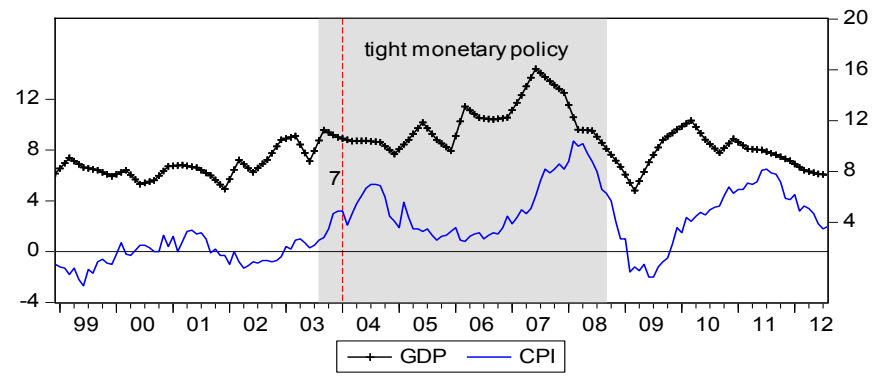

Fig. 5 Break of money supply, real GDP and CPI change within period implementing tight monetary policy Note: GDP (right scale, \%), CPI (left scale, \%)

Table 9 the real effects of tight monetary policy on GDP and CPI

\begin{tabular}{cccccccc}
\hline \multirow{2}{*}{ break } & Date & \multicolumn{3}{c}{ Post-break trend } & \multicolumn{2}{c}{ effectiveness of the impact } & Reasons for the inefficacy \\
\cline { 3 - 5 } & & Money supply & GDP & CPI & on GDP & on CPI & \\
\hline 7 & $2003: 12$ & downward & downward & upward & effective & ineffective & $\begin{array}{c}\hat{\gamma} \text { almost equals to zero; } \\
\text { The interest rate of excess reserve } \\
\text { fell synchronously. }\end{array}$ \\
\hline
\end{tabular}

\section{The Transmission Channels}

In this section the evidence regarding the transmission channelsthrough which monetary policy affect real economy will be discussed? The candidate channelsfor monetary transmission are essentially three: monetary channel (interestrate), the credit channel (lending activities) and the exchange rate channel.The first operates through investments and consumptions, high interest rates depressinvestments and consumptions. The second operates through investments and consumption too. Thepresence of rigidities and frictions in the banking system can affect economysince the amount of loans to families and companies can be limited by factorsother than interest rate. The latter operates through imports and exports. The first channel is essentially discussed in this article because it is generally considered the most important and most effective transmission channel of monetary policy.

Figure 6 and 7 show the impact of interest rates on investment and consumption. Sudden change in the level, slope or both at the time of a break would generally result in altering current interest rate or keeping the interest rate staying in a certain level which is relatively higher or lower comparing to the former one.

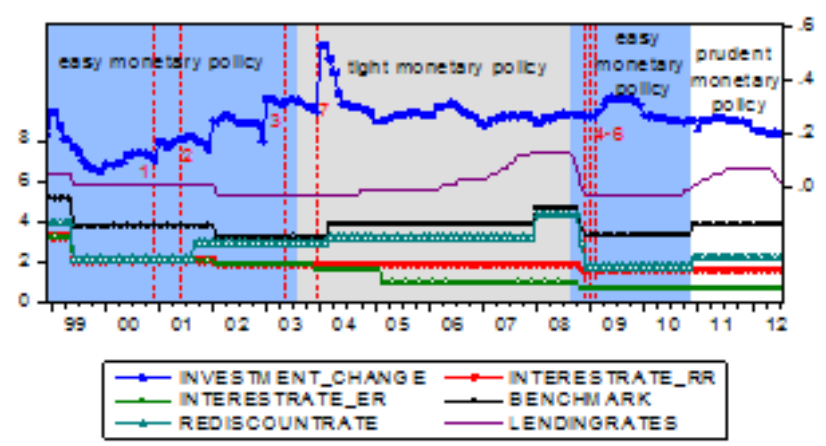

Fig. 6 Investment and interest rates

Note: investment change (right scale, \%), interest rates (left scale, \%)

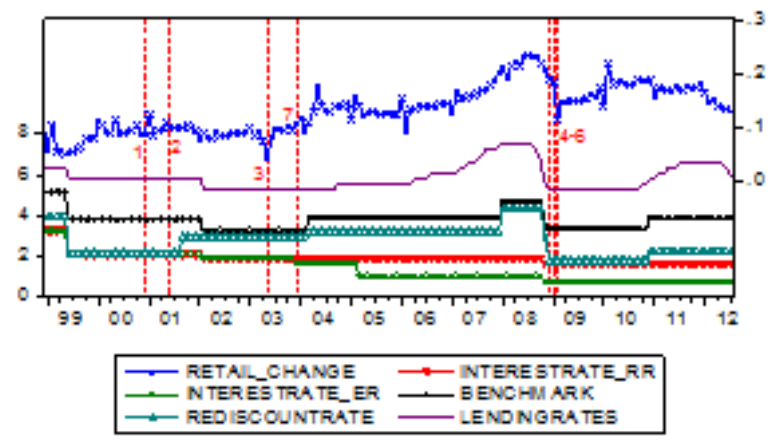

Fig, 7Consumption and interest rates Note: retail change (right scale, \%), interest rates (left scale, \%)

According to Figure 6 and 7, all of interest rates decline dramatically in June 1999. The structural change of M2 at 2000:12allowsinterest rates stay in the relative lower levels. Even 
though the impact looks obvious for the post-break investment during 2000:12-2001:05, it is weak for the consumption because of the little positive value of, and thus no even lower interest rates appear within this period. The 2 nd break makes it possible that interest rates could be further reduced, and thereby the investment and consumption could be stimulated. However, PBOC increases the discounter rate, which usually should be cut in the days applying the easy monetary policy, even though financial institutions' benchmark lending rate, central bank's benchmark lending rate, required deposit reserve rate, excess deposit reserve rate, etc. are all decreased during 2001:06-2003:05. The contradictory policy for interest rates results in the inefficacy of the impact of M2 break on post-break consumption within this period. The 3rd break of monetary aggregates at 2003:05allows all of interest rates accept the rediscount rate to continue to keep in the low level, which often conduce to the boom of investment and consumption. Before the 4th, 5th and 6th breaks appear, all of brank rates have been cut dramatically. Therefore, these breaks occurring in the end of 2008 or the early 2009 result in all of interest rates staying at very low level, and thus push post-break investment and consumption upward. China's monetary policy is effective in dealing with the financial crisis. The only break which would theoretically depress the economy in this article is the 7 th breakpoint at 2003:12. The central bank's benchmark lending rate, rediscount rate, financial institutions' benchmark lending rate increased during 2003:12-2008:08, but excess deposit reserve rate decreased at 2003:12 and 2005:03. From bank rates' perspective, this could explain the over-demand tendency of consumption during the period implementing tight monetary policy.

Table 10The impact of interest rates on investment and consumption

\begin{tabular}{|c|c|c|c|c|c|c|c|c|c|c|}
\hline \multirow[b]{2}{*}{ break } & \multirow{2}{*}{$\begin{array}{c}\text { post-break period } \\
\text { (only for } \\
\text { consumption in } \\
\text { brackets) }\end{array}$} & \multicolumn{5}{|c|}{ interest rate } & \multicolumn{2}{|c|}{ post-break trend } & \multicolumn{2}{|c|}{ effectiveness of M1 or M2 break } \\
\hline & & benchmark & rediscount & lending & $\begin{array}{l}\text { required } \\
\text { reserve }\end{array}$ & $\begin{array}{l}\text { excess } \\
\text { reserve }\end{array}$ & investment & consumption & $\begin{array}{c}\text { on post-break } \\
\text { investment }\end{array}$ & $\begin{array}{l}\text { on post-break } \\
\text { consumption }\end{array}$ \\
\hline 1 & 2000:12-2001:05 & $\bullet$ & $\bullet$ & $\bullet$ & $\bullet$ & $\bullet$ & $\uparrow$ & $\uparrow$ (slightly) & effective & effective \\
\hline 2 & 2001:06-2003:04 & $\downarrow$ & $\uparrow$ & $\downarrow$ & $\downarrow$ & $\downarrow$ & $\uparrow$ & $\downarrow$ & effective & ineffective \\
\hline 3 & 2003:05-2003:11 & $\bullet$ & $A$ & $\bullet$ & $\bullet$ & $\bullet$ & $\downarrow$ & $\uparrow$ & ineffective & effective \\
\hline 4 & $\begin{array}{c}2008: 12-2009: 09 \\
(2008: 12-2010: 02)\end{array}$ & $\bullet$ & $\bullet$ & $\bullet$ & $\bullet$ & $\bullet$ & $\uparrow$ & $\uparrow$ & effective & effective \\
\hline 5 & $\begin{array}{l}\text { 2009:01-2009:09 } \\
(2009: 01-2010: 02)\end{array}$ & $\bullet$ & $\bullet$ & $\bullet$ & $\bullet$ & $\bullet$ & $\uparrow$ & $\uparrow$ & effective & effective \\
\hline 6 & $\begin{array}{c}\text { 2009:02-2009:09 } \\
(2009: 02-2010: 02)\end{array}$ & $\bullet$ & $\bullet$ & $\bullet$ & $\bullet$ & $\bullet$ & $\uparrow$ & $\uparrow$ & effective & effective \\
\hline 7 & 2003:12-2008:08 & $\uparrow$ & $\uparrow$ & $\uparrow$ & $\bullet$ & $\downarrow$ & $\downarrow$ & $\uparrow$ & effective & ineffective \\
\hline
\end{tabular}

Note: the symbols $\uparrow, \downarrow, \uparrow$, a denote up, down, changeless (lower than before), changeless (higher than before) respectively.

From the table above, it's clear know that: (1) comparing to their former data, all bank rates keep in the lower levels during the post-break periods corresponding to break 1, 4, 5 and 6, thus makes the impact of M1 or M2 break works effectively on both of investment and consumption; (2) for break 2 or 7, the structural change of money supply impact either investment or consumptionineffectively due to the conflicting interest rate policy.

\section{CONCLUSIONS}

This article investigates the real effectsof monetary policy in China during the period from 1998:12 to 2012:08. As to evaluation of the performance of monetary policy, the structural changes of monetary aggregates should be taken into account because the structural change of time series of money supply is likely to result in the dramatic fluctuation of the economy. Different from the cointegrationmethodology flooding the empirical literature, thenew means of structural change analysisis applied for studying in this paper. 
Depending on the big financial events happened during 1998:12-2012:08, it is apparent that China's monetary authority actually implemented easy monetary policy during 1998:122003:08 and 2008:09-2010:11, tight monetary policy during 2003:09-2008:08 and prudent monetary policy during 2010:12-2012:08. The study shows that the sudden changes of money supply at 2003:05, the end of 2008 and the early of 2009 make China's monetary policy work efficiently, but these don't happen at 2000:12, 2001:06 and 2003:12. That is to say, China's monetary policy is not always effective during the period 1998:12-2012:08.

After investigating the most important transmission channel of monetary policy, this article draws the conclusion that the conflicting interest rate policy contrary to the overall objective of the central bank often makes a given money policy work inefficiently.For example, one of reasons for the structural break at 2003:12 doesn't play a more effective role in tightening the economy is that the interest rate of excess deposit reserve declined from $1.89 \%$ to $1.62 \%$ in December 2003, which offsets the constrictive effect of the 7th break.Therefore, it matters profoundly in achieving the main objective of central bankto ensure interest rate policy consistency in a given period.The findings in this article providea new perspective for the effect evaluation of monetary policy.

\section{ACKNOWLEDGMENTS}

I acknowledge the research support of Shantou University via Grants STF 13012 and SR13002.

\section{APPENDIX A: DATA SOURCES}

IFS CD-ROM, IMF:Monthly data of M1 and M2 from December 1998 to April 2012, Billions of Yuan; CPI \% change from December 1998 to May 2012; PPI \% change from January 2000 to April 2012; Share prices from December 1998 to May 2012; Central Bank Discount Rates from December 1998 to April 2012; Deposit rates (central bank, 1 year) from December 1998 to April 2012; lending rates (central bank, 1 year) from December 1998 to April 2012; GDP volume \% change (2001Q1-2012Q3).

PBOC(China's Central Bank): Monthly data of M1 and M2 from May 2012 to August 2012, Billions of Yuan; Deposit rates (central bank, 1 year) from December May 2012 to August 2012; lending rates (central bank, 1 year) from May 2012 to August 2012; central bank's benchmark interest rates (lending rates to financial institutes, 1 year, data from December 1998 to August 2012); CGPI \% change (1998m12-2012m08); required deposit reserve rate from December 1998 to August 2012; excess deposit reserve rate from December 1998 to August 2012.

National Bureau of Statistics of China: CPI \% change for June 2012 to August 2012; PPI \% change from December 1998 to December 1999; GDP volume \% change (1998Q4-2000Q4); retail change (total retail sales of consumer goods) from December 1998 to August 2012; investment change from December 1998 to August 2012.

\section{Appendix B: Histograms and Density Plots of $\inf _{\lambda \in \Lambda} t_{\hat{\alpha}^{i}}(\lambda)$}

(5,000 replicationsunder the null hypothesis $\Delta_{\mathrm{YT}}={ }_{\mathrm{t}}$ with $\left.165 \mathrm{observations}\right)$ 

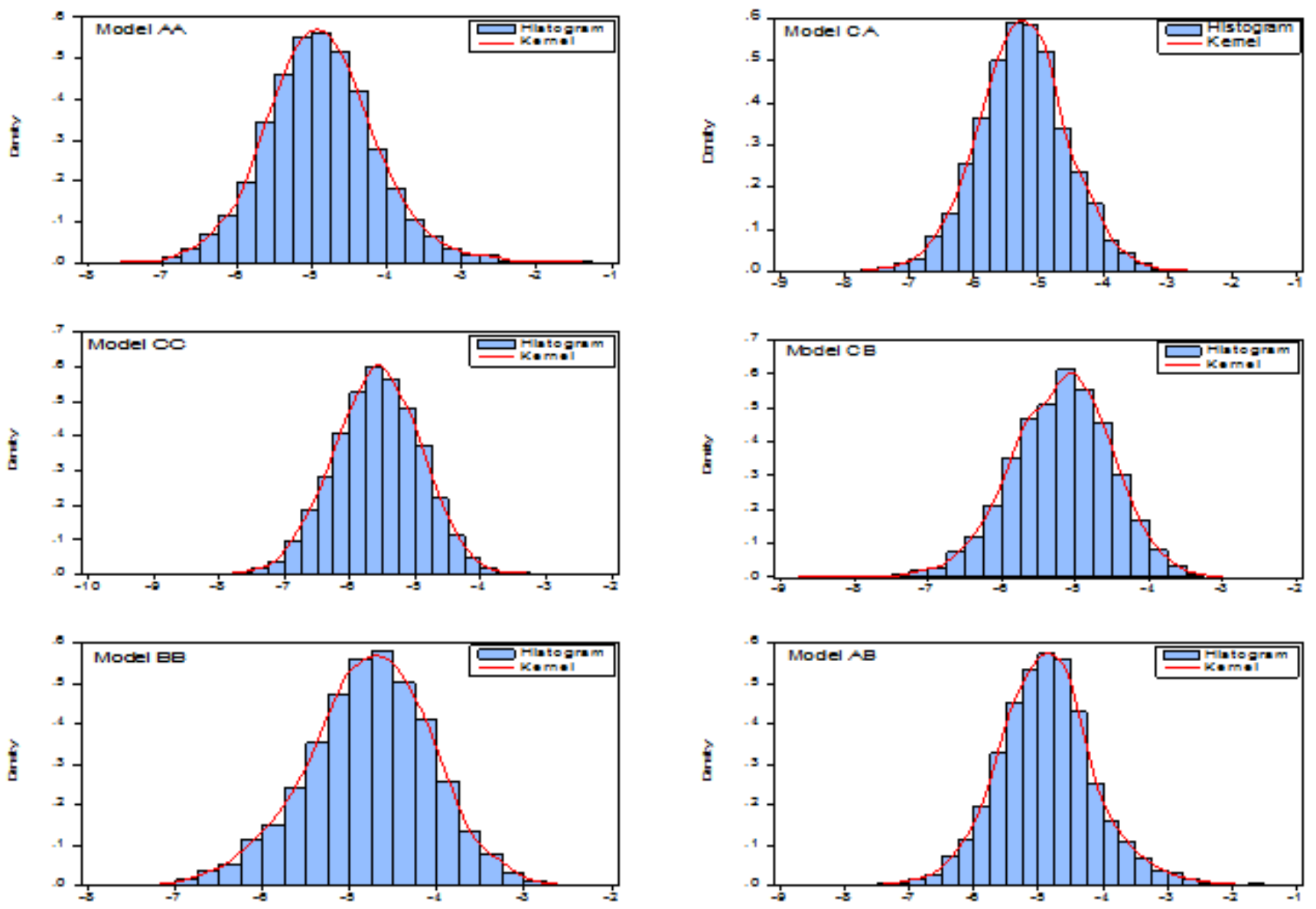

\section{References}

Andrews, D. W. K. (1993) Tests for Parameter Instability and Structural Change with Unknown Change Point, Econometrica, 61, 821-856.

Ben-David, D., Lumsdaine, R. and Papell, D. (2003) Unit Roots, Postwar Slowdowns and Long-run Growth: Evidence from Two Structural Breaks, Empirical Economics, 28, 303-319.

Berument, H. and Doğan, B (2003) Openness and the effectiveness of monetary policy: empirical evidence from Turkey, Applied Economics Letters, 10, 217-221.

Campbell, J. Y. and Mankiw, N. G. (1988) Are Output Fluctuations Transitory, Quarterly Journal of Economics, 102, 857-880.

Chow, G. C. (1960) Tests of Equality between Sets of Coefficients in Two Linear Regressions, Econometrica, 28, 591-605.

Dickey, D. A. and Fuller, W. A. (1981) Likelihood Ratio Statistics for Autoregressive Time Series with a Unit Root, Econometrica, 49, 1057-1072.

Djurić, P. M., Kay, S. M. andBoudreaux-Bartels, G. F. (1992) Segmentation of Nonstationary Signals, Proceedings of the IEEE ICASSP, San Francisco, 5, 161-164.

Goodwin, T., Safarzadeh, M. and Willett, T. (1994) Market Structure and the Effectiveness of Monetary Policy: A Cross-industry Study.Applied Economics, 26, 73-82.

Kruse, R. (2009) A New Unit Root Test against ESTAR Based on a Class of Modified Statistics, Stat Papers, Springer-Verlag.

Lumsdaine, R. L. and Papell, D. H. (1997) Multiple Trend Breaks and the Unit-root Hypothesis, The Review of Economics and Statistics, 79, 212-218. 
Nelson, C. R. and Plosser, C. (1982) Trends and Random Walks in Macroeconomic Time Series: Some Evidence and Implications, Journal of Monetary Economics, 10, 139-162.

Papell, D. H., and Prodan, R. (2007) Restricted Structural Change and the Unit Root Hypothesis, Economic Inquiry, 45, 834-853.

Perron, P. (1988) Thends and Random Walks in Macroeconomic Time Series: Further Evidence from a New Approach, Journal of Economic Dynamics and Control, 12, 473-496.

Perron, P. (1989) the Great Crash, the Oil Price Shock, and the Unit-Root Hypothesis, Econometrica, 57, 13611401.

Phillips, P. C. B. and Perron, P. (1988) Testing for a Unit Root in Time Series Regression, Biometrika, 75, 335-346.

Quandt, R. E. (1960) Tests of the Hypothesis that a Linear Regression Obeys Two Separate Regimes, Journal of the American Statistical Association, 55, 324-330.

Saxegaard, M. (2006) Excess Liquidity and Effectiveness of Monetary Policy: Evidence from Sub-Saharan Africa, IMF Working Paper, WP/06/115, 1-52.

Wang, Z. Q., Tian Y. B. and Wang S. Y. (2009)On structural change in China's import and export, Systems Engineering - Theory \& Practice, 2, 10-17.

Wasserfallen, W. (1986) Non-Stationarities in Macro-Economic Time Series - Further Evidence and Implications, Canadian Journal of Economics, 19, 498-510.

Zivot, E., and D. W. K.Andrews, (1992) Further Evidence on the Great Crash, the Oil-Price Shock, and the Unit-Root Hypothesis, Journal of Business and Economic Statistics, 10, 251-270. 